\title{
Variation in Genetic Mechanisms for Plumage Polymorphism in Skuas (Stercorarius)
}

\author{
Kirstin Janssen, Jan Ove Bustnes, and Nicholas I. Mundy
}

From the Department of Natural Sciences, Tromsø University Museum, N0-9037 Tromsø, Norway (Janssen); the Centre of Forensic Genetics, Institute of Medical Biology, Faculty of Health Sciences, UIT The Arctic University of Norway, N0-9037 Tromsø, Norway (Janssen); the Norwegian Institute for Nature Research, The Fram Centre, N0-9296 Tromsø, Norway (Bustnes); and the Department of Zoology, University of Cambridge, Downing Street, Cambridge CB2 3EJ, UK (Mundy).

Address correspondence to N. I. Mundy at the address above, or e-mail: nim21@cam.ac.uk.

Corresponding Editor: Eduardo Eizirik

\begin{abstract}
Coloration is evolutionarily labile and so provides an excellent trait for examining the repeatability of evolution. Here, we investigate the repeatability of the evolution of polymorphic variation in ventral plumage coloration in skuas (Stercorarius: Stercorariidae). In 2 species, arctic (S. parasiticus) and pomarine skuas (S. pomarinus), plumage polymorphism was previously shown to be associated with coding changes at the melanocortin-1 receptor $(M C 1 R)$ locus. Here, we show that polymorphism in a third species, the south polar skua ( $S$. maccormicki), is not associated with coding variation at $M C 1 R$ or with variation at a Z-linked second candidate locus, tyrosinase-related protein 1 (TYRP1). Hence, convergent evolution of plumage polymorphisms in skuas is only partly repeatable at the level of the genetic locus involved. Interestingly, the pattern of repeatability in skuas is aligned not with phylogeny but with the nature of the phenotypic variation. In particular, south polar skuas show a strong sex bias to coloration that is absent in the other species, and it may be that this has a unique genetic architecture.
\end{abstract}

Subject Area: Genotype to phenotype

Key words: $M C 1 R$, melanin, repeatability of evolution, skua, TYRP1

In recent years, great strides have been made in establishing the genetic basis of color polymorphisms in wild populations in a wide variety of species (Hubbard et al. 2010; San-Jose and Roulin 2017), making coloration an important model system for understanding the genetic basis of adaptation. An important unresolved issue is the repeatability of color evolution, that is, the extent to which convergent changes in phenotype are due to convergent genetic changes (Stern and Orgogozo 2009; Arnaud and Orgogozo 2013). There are cases where color evolution is at least to some extent repeatable, particularly at the level of the loci involved (Manceau et al. 2010; Kronforst et al. 2012). However, far more evidence is needed to quantify this issue and, more importantly, to explain the causes of the patterns that are found. For terrestrial vertebrates, the majority of information on the genetic basis of color variation comes from melanin-based variation, although progress is beginning to be made for other coloration mechanisms (e.g., carotenoids; Twyman et al. 2018).

Shared color polymorphisms among related species are a special case in relation to repeatability. In such cases, there may have been convergent evolution of the polymorphism, but an alternative possibility is that the polymorphism arose a single time in a common ancestor, and was subsequently maintained across speciation events (Jamie and Meier 2020). While such "trans-specific" evolution is well-known for some highly polymorphic systems (e.g., MHC, Klein et al. 2007; self-incompatibility, Richman et al. 1996), the data for color polymorphisms are currently limited. 
Birds are an excellent group of vertebrates to address these issues since there are several avian genera with a similar polymorphic color variation that is shared across multiple related species (e.g., buzzards [Buteo], sparrowhawks [Accipiter], owls [Tyto], and egrets [Aigretta]; Roulin 2004). Genera with multiple polymorphic species, for which there are some genetic data, include skuas (Stercorarius; Mundy et al. 2004; Janssen and Mundy 2017), falcons (Falco; Gangoso et al. 2011; Johnson et al. 2012; Zhan et al. 2012), and boobies (Sula; Baião et al. 2007; Baião and Parker 2012). There are also examples of convergent evolution in different populations of the same species (e.g., Uy et al. 2016). Results from these studies are variable, some implicating the same locus in convergent evolution, whereas in others different loci are involved.

The skuas (Stercorarius) are kleptoparasitic seabirds that include 3 species with well-defined ventral melanin-based plumage polymorphisms (Furness 1987). It has previously been shown that in 2 polymorphic species, the arctic ( $S$. parasiticus) and pomarine skua (S. pomarinus), color variation has evolved independently by mutations in the melanocortin-1 receptor $(M C 1 R)$, and some of the mutations implicated in color variation have occurred independently in the 2 lineages (Mundy et al. 2004; Janssen and Mundy 2013, 2017). The third species is the south polar skua (S. maccormicki), one of the great skua species (previously comprising the genus Catharacta), which is more closely related to pomarine than arctic skuas (Braun and Brumfield 1998). Three color morphs have been defined in the south polar skua, with ventral plumage coloration varying from pale buff in the pale morph to dark brown in the dark morph (Figure 1; Ainley et al. 1985; Olsen and Larsson 1997). As in the arctic skua, there is a latitudinal cline in plumage coloration, with dark morph birds more common in warmer areas and pale morph birds more common in cooler areas. In addition, and unlike the arctic and pomarine skuas, there is sex-specific variation in plumage color in south polar skuas, with males being on average darker than females (although the 3 color morphs are present in both sexes, Ainley et al. 1985). While plumage coloration in south polar skuas is presumed to be under genetic control, there are no studies of genetic transmission of coloration across generations. Additionally, there is little information on the fitness consequences of plumage color variation in this species. In the best-studied species, the arctic skua, the most favored adaptive hypothesis for the maintenance of the polymorphism is apostatic selection (Árnason 1978, Arcos 2007), a type of negative frequency-dependent selection in which rare morphs would have an advantage in pursuit of prey, but there is also some evidence for

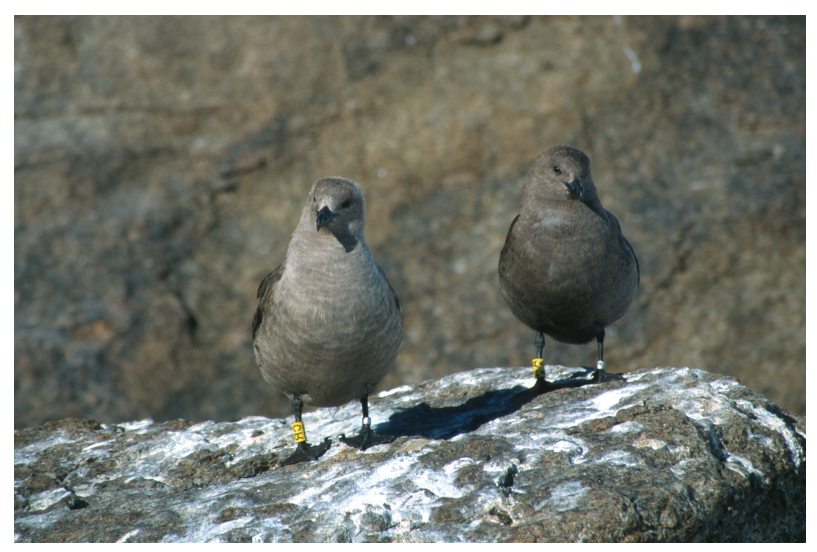

Figure 1. Typical color variation in the south polar skua. Pale morph female on the left and dark morph male on the right. (Photo credit: J.O.B.). sex-specific selection on coloration (Janssen et al. 2006). We previously showed that the plumage polymorphisms in the arctic and pomarine skua were not present in their common ancestor (Janssen and Mundy 2017), but it remains possible that a polymorphism arose in the ancestor of the pomarine and great skuas and was retained in the south polar skua lineage.

The genetic basis of plumage color variation in south polar skuas has not been previously investigated. Here, we examine whether the evolution of plumage polymorphism in this species has occurred by the same genetic mechanisms as in the other skuas. In order to achieve this, we assay variation at 2 candidate coloration loci. The first candidate, $M C 1 R$, was previously implicated in color variation in arctic and pomarine skuas and has been shown to have sex-dependent effects on coloration in barn owls (Tyto alba; SanJose et al. 2015). The second candidate, tyrosinase-related protein 1 (TYRP1), was chosen since it has been associated with melaninbased color variation in other birds (Buggiotti 2007; Nadeau et al. 2007b; Delmore et al. 2016), and, since it is Z-linked, it is a good candidate for sex-related variation in coloration. MC1R has a critical role in regulating the type of pigment synthesized by melanocytes, whereas TYRP1 is one of the enzymes required for eumelanin synthesis (Hubbard et al. 2010).

\section{Materials and Methods}

\section{Samples}

Plumage phenotype data and blood samples from adult south polar skuas caught on the nest were collected at Svarthamaren $71^{\circ} 53^{\prime} 0^{\prime \prime} \mathrm{S}$, $5^{\circ} 10^{\prime} 0^{\prime \prime} \mathrm{E}$ in Dronning Maud Land, Antarctica, in December 2001 and January 2002 (Bustnes et al. 2006). The plumage phenotype of 64 birds was visually categorized as "pale," "intermediate," or "dark" by a single experienced observer (J.O.B.). In south polar skuas, dark morph individuals are distinct, whereas continuous variation is present between pale and intermediate morphs (Ainley et al. 1985). The individuals' sex was determined by molecular analyses as described previously (Bustnes et al. 2006). A total of 25 individuals comprising 8 pale birds ( 5 females and 3 males), 7 intermediate birds ( 5 females and 2 males), and 10 dark birds ( 2 females and 8 males) were chosen for the analysis of candidate pigmentation genes.

\section{Laboratory and Statistical Methods}

Genomic DNA was extracted from blood samples using standard sodium dodecyl sulfate (SDS) lysis and proteinase K digestion followed by phenol-chloroform extraction and ethanol precipitation protocols (Sambrook et al. 1989). MC1R genotypes from the 25 individuals were obtained as part of a previous study (Janssen and Mundy 2017). Briefly, 846 bp of the coding sequence of MC1R gene including all of the sites known to be involved in color variation in other vertebrates, and 285 bp of $5^{\prime}$ upstream sequence was amplified and directly sequenced.

For TYRP1, exon 3 was initially sequenced in the 25 individuals since this exon is the site of coloration-changing mutations in other birds and mammals (Gratten et al. 2007; Nadeau et al. 2007b). Subsequent analyses extended to exons $2,4,5$, and 6 , screening one individual of each sex-plumage phenotype combination for each exon $(N=6)$. Primers used to amplify and sequence exons 2 to 6 are listed in Table 1. Amplifications were carried out in $15 \mu \mathrm{L}$ reaction volumes containing $1 \times$ CoralLoad PCR, including $1.5 \mathrm{mM} \mathrm{MgCl}$, 1× Q-solution, $200 \mu \mathrm{M}$ of each dNTP, $0.4 \mu \mathrm{M}$ of each primer, 3.75 units Taq (Qiagen Taq PCR Core kit) (Qiagen, Manchester, UK), and 


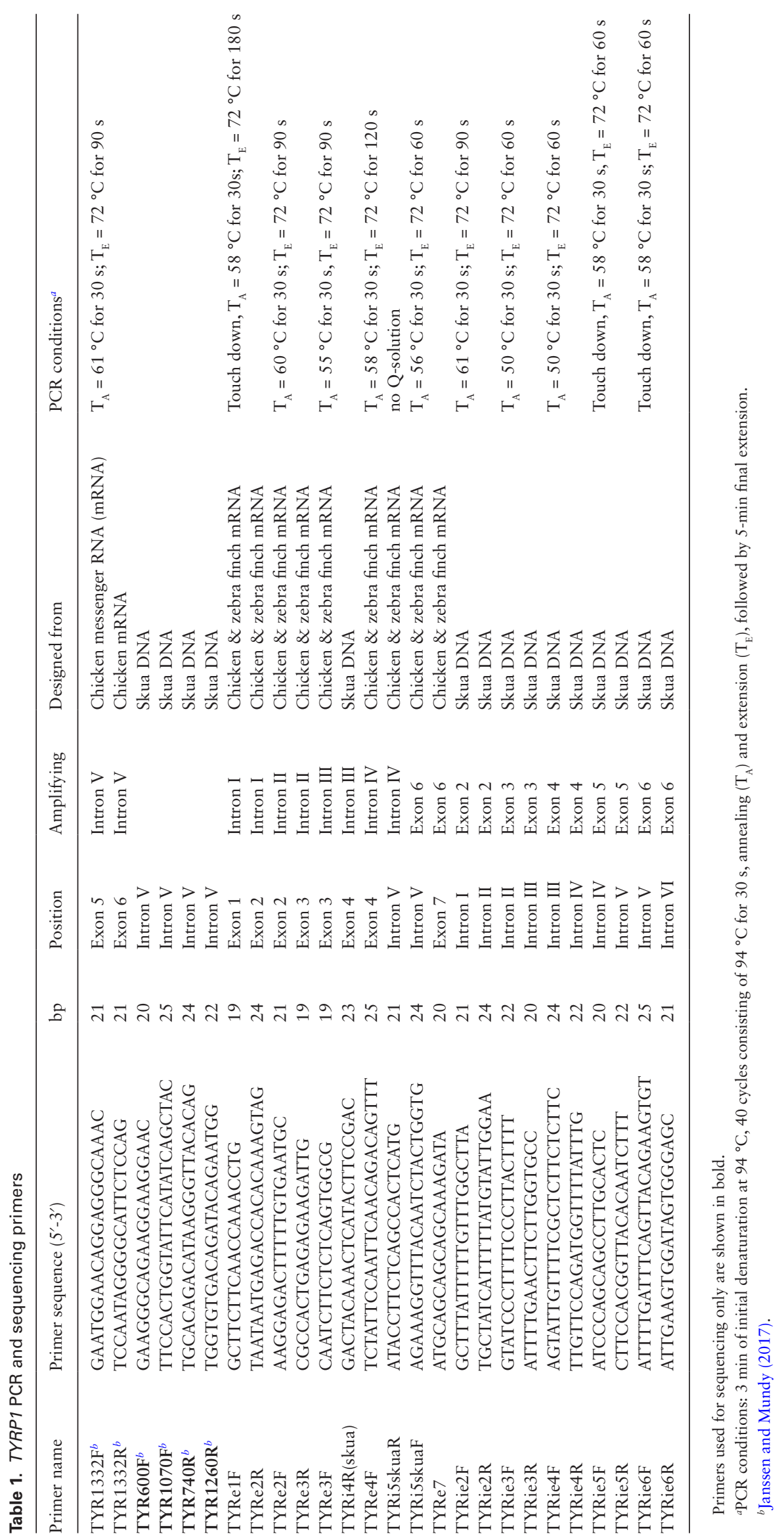


approximately 50 ng DNA. For detailed Polymerase chain reaction (PCR) conditions, see Table 1. Excess primers and nucleotides were either removed using the QIAGEN purification kit or EXOSAP-IT (Amersham Biosciences, Little Chalfont, UK). All amplification products were Sanger sequenced on both strands with Big Dye v.3.1 (Applied Biosystems, Warrington, UK) at the sequencing facilities of the University of Oxford, UK, and the University Hospital of Tromsø, Norway.

Sequence data were edited with Bioedit v7.2.5 (Hall 1999). Tests for association between plumage coloration and sex, and between plumage coloration and genotype, were conducted using Fisher's exact tests with the fisher.test function in R studio (RStudio Team 2020).

\section{Results}

\section{Association Between Sex and Plumage Coloration}

In the full sample of 64 individuals, there were 15 dark, 3 intermediate, and 4 pale males and 2 dark, 6 intermediate, and 34 pale females. Coloration was significantly associated with sex, with males being darker than females $(2 \times 3$ Fisher's exact test, $P<0.001)$, which concurs with previous findings (Ainley et al. 1985).

\section{Association Between Genetic Variation at Candidate Loci and Plumage Coloration}

At the MC1R locus (1171 bp, $N=25$ ), there were 2 variable sites in south polar skuas, one non-synonymous Single-nucleotide polymorphism (SNP), leading to a glutamate to lysine (E12K) substitution and one synonymous SNP, defining 2 haplotypes at MC1R. One haplotype (with E12; Genbank Accession MG515660.1) was sequenced once from a single individual (a dark morph male) and is shared with the closely related monomorphic brown skua (S. lonnbergii; Janssen and Mundy 2017). The second haplotype (with K12; Genbank Accession MG515661.1) was present as 49 copies in our sample and has not been found in other skua species. Thus, unlike the situation with arctic and pomarine skuas, MC1R variation is not associated with plumage color variation in the south polar skua.

The 5 exons at TYRP1 (exons 2-6) were completely sequenced (exon 3 in $N=25$ birds; exons 2, 4, 5, and 6 in $N=6$ birds, total length $=1024 \mathrm{bp}$ ). No variable sites were found. Hence, no evidence was found for an association between TYRP1 and plumage coloration in the south polar skua.

\section{Discussion}

We investigated whether convergent evolution of melanin-based plumage coloration in south polar skuas was attributable to the same locus that accounts for convergent evolution of a similar phenotype in 2 other species of skua. The results clearly indicate that this is not the case and do not implicate $M C 1 R$ as a major effect locus for color variation in south polar skuas. In a sample containing extremes of color variation in both males and females, almost all birds are homozygous for the same $M C 1 R$ allele. One caveat to these findings is that we did not sequence the last 20 codons of MC1R (out of a total of 315 ). However, the gene portion sequenced here contains all of the sites previously shown to be functionally important in birds and other vertebrates (Theron et al. 2001; Mundy 2005; Cibois et al. 2011), so it is unlikely that functional variation is present in this region. In addition, we only sequenced $285 \mathrm{bp}$ of $5^{\prime}$ upstream noncoding sequence of $M C 1 R$, so it remains possible that cis-regulatory mutations elsewhere at the locus affecting MC1R expression contribute to the color variation. There is currently little information on cis-regulatory mutations at MC1R influencing coloration, although some recent whole-genome studies suggest that they may occur in birds (Funk and Taylor 2019). Interestingly, the one divergent allele sequenced (from a dark male) is shared with the brown skua ( $S$. lonnbergii), in which this is the only MC1R allele reported (Janssen and Mundy 2017). This may be due to introgression since hybridization occurs between south polar and brown skuas (Ritz et al. 2006), although there are other potential mechanisms such as incomplete lineage sorting. The allele has an E12K mutation associated with dark coloration in arctic and pomarine skuas, and brown skuas have uniform dark brown coloration. Although this mutation might plausibly affect coloration in south polar skuas, it is clearly not implicated in the main coloration variation present in this species. Since we have excluded a role for the same coding variants of MC1R to be involved in plumage polymorphism in south polar and pomarine skuas, we conclude that the plumage polymorphisms evolved independently in the 2 species.

The color variation in south polar skuas differs in important respects from that in arctic and pomarine skuas. Most importantly, coloration in south polar skuas is sex-biased, which we confirmed here. Although most cases in which $M C 1 R$ variation has been associated with plumage polymorphism do not involve sex differences in coloration, MC1R has been occasionally linked to sexual variation in coloration (barn owl [Tyto alba]; San-Jose et al. 2015) and so was a plausible candidate for south polar skuas. In addition, MC1R has been implicated in other sex-specific effects, such as the evolution of sexual dichromatism in birds (Nadeau et al. 2007a), and sex-specific pain reception in mammals (Mogil et al. 2003). Nevertheless, it is possible that $M C 1 R$ is less likely to be involved in cases of sex-biased coloration. In addition, whereas continuous variation between pale and intermediate morphs is present in south polar skuas, with dark morphs being distinct, in arctic skuas, it is the pale morph that is distinct, and there is continuous variation between intermediate and dark morphs. However, the consequences of this difference for genetic architecture are unclear. In addition to well-known association with discrete color polymorphisms, we note that MC1R is a major effect locus underlying quantitative color variation in numerous cases (e.g., dark/intermediate arctic skuas, blue phase snow geese [Chen caerulescens], Mundy et al. 2004; beach mice [Peromyscus polionotus], Steiner et al. 2007).

The sex-biased coloration informed our choice of another candidate locus, the TYRP1 locus, which is Z-linked in birds (April et al. 1998). We found no variation in the 5 exons of TYRP1 that were targeted, and hence no evidence that sequence variation in TYRP1 is associated with the polymorphism. We chose this segment of the locus since it is the site of mutations that lead to color variation in other species, notably Japanese quail (Nadeau et al. 2007b), but cannot rule out the possibility that variation in the remaining exons contributes to color variation. In addition, it remains possible that gene dosage effects on the expression of TYRP1 among females and males could contribute to sex-specific differences in coloration, which would be interesting to explore further.

An obvious next step to identify genetic variation contributing to the plumage polymorphism in south polar skuas would be to conduct a Genome-wide association study (GWAS), an approach that has succeeded in uncovering candidate loci affecting melanin coloration in other birds (crows, Poelstra et al. 2014; wood warblers, Toews et al. 2016; Swainson's thrushes, Delmore et al. 2016; and ruff, Küpper et al. 2016). The low level of genetic variation in south 
polar skuas, which is presumably related to a low effective population size resulting from a founder event (Ritz et al. 2008), would increase the power of this approach (Braun and Brumfield 1998; Janssen and Mundy 2017).

Other studies on polymorphisms within or between multiple avian species offer interesting contrasts. In falcons and boobies, there is evidence that the same locus $(M C 1 R)$ is involved in melanic polymorphisms in multiple species (Baião et al. 2007, 2012; Gangoso et al. 2011; Johnson et al. 2012; Zhan et al. 2012). However, we are not aware of any cases where polymorphism due to the same locus evolved ancestrally and was retained through subsequent speciation(s). In Solomon Islands flycatchers and crows, subspecies or populations in a species complex show evidence of differing loci in the same pathway being involved in convergent evolution of melanic coloration (Uy et al. 2009, 2016; Poelstra et al. 2014; Vijay et al. 2016). All of these examples involve sexually monomorphic coloration. In conclusion, it may be that genetic architecture for sexually varying polymorphic coloration, as in the south polar skua, differs from that for sexually monomorphic coloration.

\section{Funding}

Norwegian Research Council (field study to J.O.B. and post-doctoral grant (170838) to K.J.); Norwegian Institute for Nature Research.

\section{Acknowledgments}

We are grateful to the staff at the Norwegian Research Station (Troll) in Antarctica and Øystein Varpe and John A. Henden for field assistance. The permit to collect samples from south polar skuas was granted by the Norwegian Polar Institute, in accordance with the regulations relating to the protection of the environment in Antarctica, and the National Animal Health Inspection/Norwegian Food Safety Authority.

\section{Data Availability}

We have deposited the new primary data underlying these analyses as follows: DNA sequences: Genbank accession MZ488491.

\section{References}

Ainley DG, Spear LB, Wood RC. 1985. Sexual color and size variation in the south polar skua. Condor. 87:427-428.

April CS, Jackson IJ, Kidson SH. 1998. The cloning and sequencing of a cDNA coding for chick tyrosinase-related protein-1. Biochim Biophys Acta. 1395:7-12.

Arcos JM. 2007. Frequency-dependent morph differences in kleptoparasitic chase rate in the polymorphic arctic skua Stercorarius parasiticus. J Ornithol. 148:167-171.

Árnason E. 1978. Apostatic selection and kleptoparasitism in the parasitic jaeger. Auk. 95:377-381.

Arnaud M, Orgogozo V. 2013. The loci of repeated evolution: a catalog of genetic hotspots of phenotypic variation. Evolution. 67:1235-1250.

Baião PC, Parker PG. 2012. Evolution of the melanocortin-1 receptor (MC1R) in Boobies and Gannets (Aves, Suliformes). J Hered. 103:322-329.

Baião PC, Schreiber E, Parker PG. 2007. The genetic basis of the plumage polymorphism in red-footed boobies (Sula sula): a melanocortin-1 receptor (MC1R) analysis. J Hered. 98:287-292.

Braun MJ, Brumfield RT. 1998. Enigmatic phylogeny of skuas: an alternative hypothesis. Proc Roy Soc B. 265:995-999.

Buggiotti L. 2007. Avian evolutionary genomics: studies of Ficedula flycatchers $[P h D$ thesis $]$. University of Turku, Finland.
Bustnes JO, Tveraa T, Henden JA, Varpe O, Janssen K, Skaare JU. 2006. Organochlorines in Antarctic and Arctic avian top predators: a comparison between the South Polar Skua and two species of northern hemisphere gulls. Environ Sci Technol. 40:2826-2831.

Cibois A, Thibault JC, Pasquet E. 2011. The molecular basis of the plumage colour polymorphism in the Tahiti reed-warbler Acrocephalus caffer. $J$ Avian Biol. 43:3-8.

Delmore KE, Toews DP, Germain RR, Owens GL, Irwin DE. 2016. The genetics of seasonal migration and plumage color. Curr Biol. 26:21672173.

Funk ER, Taylor SA. 2019. High-throughput sequencing is revealing genetic associations with avian plumage color. Auk. 136:1-7.

Furness RW. 1987. The skuas. Waterhouses (UK): T \& A. D. Poyser.

Gangoso L, Grande JM, Ducrest AL, Figuerola J, Bortolotti GR, Andrés JA, Roulin A. 2011. MC1R-dependent, melanin-based colour polymorphism is associated with cell-mediated response in the Eleonora's falcon. $J$ Evol Biol. 24:2055-2063.

Gratten J, Beraldi D, Lowder BV, McRae AF, Visscher PM, Pemberton JM, Slate J. 2007. Compelling evidence that a single nucleotide substitution in TYRP1 is responsible for coat colour polymorphism in a free living population of Soay sheep. Proc Roy Soc B. 274:619-626.

Hall TA. 1999. BioEdit: a user-friendly biological sequence alignment editor and analysis program for Windows 95/98/NT. Nucl Acids Symp Ser. 41:95-98.

Hubbard JK, Uy JA, Hauber ME, Hoekstra HE, Safran RJ. 2010. Vertebrate pigmentation: from underlying genes to adaptive function. Trends Genet. 26:231-239.

Jamie GA, Meier JI. 2020. The persistence of polymorphisms across species radiations. Trends Ecol Evol. 35:795-808.

Janssen K, Erikstad KE, Bensch S. 2006. Offspring sex ratio allocation in the parasitic jaeger: selection for pale females and melanic males. Behav Ecol. 17:236-245.

Janssen K, Mundy NI. 2013. Molecular population genetics of the melanic plumage polymorphism in Arctic skuas (Stercorarius parasiticus): evidence for divergent selection on plumage colour. Mol Ecol. 22:4634-4643.

Janssen K, Mundy NI. 2017. The genetic basis and enigmatic origin of melanic plumage polymorphism in pomarine skuas (Stercorarius pomarinus). Proc Roy Soc B. 284:20171735.

Johnson JA, Ambers AD, Burnham KK. 2012. Genetics of plumage color in the Gyrfalcon (Falco rusticolus): analysis of the melanocortin-1 receptor gene. J Hered. 103:315-321.

Klein J, Sato A, Nikolaidis N. 2007. MHC, TSP, and the origin of species: from immunogenetics to evolutionary genetics. Annu Rev Genet. 41:281-304.

Kronforst MR, Barsh GS, Kopp A, Mallet J, Monteiro A, Mullen SP, Protas M, Rosenblum EB, Schneider CJ, Hoekstra HE. 2012. Unraveling the thread of nature's tapestry: the genetics of diversity and convergence in animal pigmentation. Pigment Cell Melanoma Res. 25:411-433.

Küpper C, Stocks M, Risse JE, dos Remedios N, Farrell LL, McRae SB, Morgan TC, Karlionova N, Pinchuk P, Verkuil YI, et al. 2016. A supergene determines highly divergent male reproductive morphs in the ruff. Nat Genet. 48:79-83.

Manceau M, Domingues VS, Linnen CR, Rosenblum EB, Hoekstra HE. 2010. Convergence in pigmentation at multiple levels: mutations, genes and function. Philos Trans R Soc Lond B Biol Sci. 365:2439-2450.

Mogil JS, Wilson SG, Chesler EJ, Rankin AL, Nemmani KV, Lariviere WR, Groce MK, Wallace MR, Kaplan L, Staud R, et al. 2003. The melanocortin-1 receptor gene mediates female-specific mechanisms of analgesia in mice and humans. Proc Natl Acad Sci U S A. 100:4867-4872.

Mundy NI. 2005. A window on the genetics of evolution: MC1R and plumage coloration in birds. Proc Roy Soc B. 272:1633-1640.

Mundy NI, Badcock NS, Hart T, Scribner K, Janssen K, Nadeau NJ. 2004. Conserved genetic basis of a quantitative plumage trait involved in mate choice. Science. 303:1870-1873.

Nadeau NJ, Burke T, Mundy NI. 2007a. Evolution of an avian pigmentation gene correlates with a measure of sexual selection. Proc Biol Sci. 274:1807-1813. 
Nadeau NJ, Mundy NI, Gourichon D, Minvielle F. 2007b. Association of a single-nucleotide substitution in TYRP1 with roux in Japanese quail (Coturnix japonica). Anim Genet. 38:609-613.

Olsen KM, Larsson H. 1997. Skuas and jaegers: a guide to the skuas and jaegers of the world. Sussex, UK: Pica Press.

Poelstra JW, Vijay N, Bossu CM, Lantz H, Ryll B, Müller I, Baglione V, Unneberg P, Wikelski M, Grabherr MG, et al. 2014. The genomic landscape underlying phenotypic integrity in the face of gene flow in crows. Science. 344:1410-1414.

Richman AD, Uyenoyama MK, Kohn JR. 1996. Allelic diversity and gene genealogy at the self-incompatibility locus in the Solanaceae. Science. 273:1212-1216.

Ritz MS, Hahn S, Janicke T, Peter HU. 2006. Hybridization between South polar skua (Catharacta maccormicki) and Brown skua (C. antarctica lonnbergi) in the Antarctic Peninsula region. Polar Biol. 29:153-159.

Ritz MS, Millar C, Miller GD, Phillips RA, Ryan P, Sternkopf V, LiebersHelbig D, Hans-Ulrich P. 2008. Phylogeography of the southern skua complex - rapid colonization of the southern hemisphere during a glacial period and reticulate evolution. Mol Phyl Evol. 49:292-303.

Roulin A. 2004. The evolution, maintenance and adaptive function of genetic colour polymorphism in birds. Biol Rev Camb Philos Soc. 79:815848.

RStudio Team. 2020. RStudio: integrated development for R. Boston: RStudio, PBC. Available from: http://www.rstudio.com/. Accessed 30 May 2021.

Sambrook J, Fritsch EF, Maniatis T, 1989. Molecular cloning. New York: Cold Spring Harbor.

San-Jose LM, Ducrest AL, Ducret V, Béziers P, Simon C, Wakamatsu K, Roulin A. 2015. Effect of the MC1R gene on sexual dimorphism in melanin-based colorations. Mol Ecol. 24:2794-2808.
San-Jose LM, Roulin A. 2017. Genomics of coloration in natural animal populations. Phil Trans Roy Soc. 372:20160337.

Steiner CC, Weber JN, Hoekstra HE. 2007. Adaptive variation in beach mice produced by two interacting pigmentation genes. PLoS Biol. 5:e219.

Stern DL, Orgogozo V. 2009. Is genetic evolution predictable? Science. 323:746-751.

Theron E, Hawkins K, Bermingham E, Ricklefs R, Mundy NI. 2001. The molecular basis of an avian plumage polymorphism in the wild: a point mutation in the melanocortin-1 receptor is perfectly associated with melanism in the bananaquit (Coereba flaveola). Curr Biol. 11:550-557.

Toews DP, Taylor SA, Vallender R, Brelsford A, Butcher BG, Messer PW, Lovette IJ. 2016. Plumage genes and little else distinguish the genomes of hybridizing warblers. Curr Biol. 26:2313-2318.

Twyman H, Prager M, Mundy NI, Andersson S. 2018. Expression of a carotenoid-modifying gene and evolution of red coloration in weaverbirds (Ploceidae). Mol Ecol. 27: 449-458.

Uy JAC, Cooper EA, Cutie S, Concannon MR, Poelstra JW, Moyle RG, Filardi CE. 2016. Mutations in different pigmentation genes are associated with parallel melanism in island flycatchers. Proc Roy Soc B. 283:20160731.

Uy JA, Moyle RG, Filardi CE, Cheviron ZA. 2009. Difference in plumage color used in species recognition between incipient species is linked to a single amino acid substitution in the melanocortin-1 receptor. Am Nat. 174:244-254.

Vijay N, Bossu CM, Poelstra JW, Weissensteiner MH, Suh A, Kryukov AP, Wolf JB. 2016. Evolution of heterogeneous genome differentiation across multiple contact zones in a crow species complex. Nat Commun. 7:13195.

Zhan XJ, Dixon A, Fox NC, Bruford MW. 2012. Missense SNP of the $M C 1 R$ gene is associated with plumage variation in the Gyrfalcon (Falco rusticolus). Anim Genet. 43:460-462. 